\title{
Preparation and characterisation of Dextran-70 hydrogel for controlled release of praziquantel
}

\author{
Flávio dos Santos Campos ${ }^{1}$, Douglas Lopes Cassimiro ${ }^{2}$, Marisa Spirandeli Crespi ${ }^{2}$, Adélia Emília \\ Almeida ${ }^{1}$, Maria Palmira Daflon Gremião, ${ }^{1, *}$
}

${ }^{1}$ School of Pharmaceutical Sciences, Universidade Estadual Paulista, Araraquara, São Paulo, Brazil, ${ }^{2}$ Institute of Chemistry, Universidade Estadual Paulista, Araraquara, São Paulo, Brazil

\begin{abstract}
A hydrogel was developed from $70 \mathrm{kDa}$ dextran (DEX-70) and praziquantel (PZQ) incorporated as a model drug. Biopharmaceutical properties, such as solubility and dissolution rate, were analysed in the design of the hydrogel. Furthermore, the hydrogel was also characterized by IR spectroscopy and DSC. Tests of the swelling rate showed that the hydrogel swelled slowly, albeit faster than the rate for the free polymer. In dissolution tests, the hydrogel released the drug slowly and continuously. This slow release was similar to that observed in the swelling tests and resulted in controlled release of the drug. Thus, this dextran is a suitable polymer for the development of hydrogels as vehicles for the controlled release of drugs.
\end{abstract}

Uniterms: Hydrogel/development. Hydrogel/biopharmaceutical properties. Dextran/hydrogel development. Praziquantel/controlled release. Hydrogel/swelling test.

\begin{abstract}
Um hidrogel foi desenvolvido a partir de dextrano $70 \mathrm{kDa}$ (DEX-70) e praziquantel incorporado (PZQ) como fármaco modelo. Propriedades biofarmacêuticas, como solubilidade e velocidade de dissolução, foram analisadas no desenvolvimento do hidrogel. Além disso, o hidrogel também foi caracterizado por espectroscopia na região do infravermelho e calorimetria diferencial exploratória (DSC). Testes da taxa de intumescimento mostraram que o hidrogel intumesce lentamente, embora tenha sido mais rápido do que a taxa do polímero livre. Nos testes de dissolução, o hidrogel liberou o fármaco lenta e continuamente. Esta liberação lenta foi semelhante a observada nos testes de intumescimento e resultou em uma liberação controlada do fármaco. Assim, o dextrano $70 \mathrm{kDa}$ é um polímero adequado para o desenvolvimento de hidrogéis como veículos para a liberação controlada de fármacos.
\end{abstract}

Unitermos: Hidrogel/desenvolvimento. Hidrogel/propriedades biofarmacêuticas. Dextrano/ desenvolvimento de hidrogel. Praziquantel/liberação controlada. Hidrogel/teste de intumescimento.

\section{INTRODUCTION}

Schistosoma mansoni infection causes intestinal schistosomiasis and is one of the most common parasitic diseases in the tropics and subtropics (Enk et al., 2008). One treatment approach for this disease is chemotherapy using praziquantel (PZQ). PZQ is a broad spectrum antihelminthic drug effective against all important species of adult flatworms and their immature forms. The poor bio-

\footnotetext{
*Correspondence: M. P. D. Gremião. Departamento de Fármacos e Medicamentos, Faculdade de Ciências Farmacêuticas de Araraquara, Universidade Estadual Paulista Júlio de Mesquita Filho. Rodovia Araraquara - Jaú, km 1 - 14801-902 - Araraquara - SP, Brasil, Caixa-postal: 512. E-mail: pgremiao@fcfar.unesp.br
}

availability of PZQ can be attributed to its fast metabolism and low water solubility (Mourão et al., 2005; USP 31, 2008). According to González-Esquivel et al. (2005), the apparent permeability coefficient of PZQ is $4.4 \times 10^{-5} \mathrm{~cm} / \mathrm{s}$. For this reason, PZQ has been classified as a Class II drug in the Biopharmaceutics Classification System (BCS) (Passerini et al., 2006; Breda et al., 2009).

Drugs such as praziquantel, as well as those which do not have any biopharmaceutical property impaired by a physicochemical property, may benefit from improved properties with the use of controlled release systems. Drug delivery in conventional dosage forms often suffers from the drawbacks of repeated drug administration and large fluctuations in blood drug levels. Controlled drug delivery 
systems are a convenient way of controlling the dosing frequency responsible for rapid absorption and distribution of drug in conventional dosage forms, and are dependent upon two intrinsic properties of the drug, namely, elimination half-life $\left(t_{1 / 2}\right)$ and therapeutic index (TI). The goal is to give a drug at a sufficient rate, frequency and dose so that the ratio $C_{\max } / C_{\min }$ in plasma at steady state is always maintained at effective concentrations during the course of therapy, reducing side effects or improving physicochemical and biopharmaceutical properties. A number of controlled release drug delivery systems such as oral, transdermal, injectable and implantable drug delivery systems have been investigated (Sood, Panchagnula, 2003; Sun et al., 2003).

In the development of controlled drug release systems, various strategies have employed polymers to modify the characteristics of the substances or particles thereby improving targeting action, prolonging release or decreasing toxicity. The use of polymers in the design of systems for controlled drug release has been intensively studied in recent years and some authors foresee major developments at the interface between the chemistry of polymers and the biomedical sciences (Takakura, Hashida, 1995; Duncan, 2003; Ettmayer et al., 2004).

The main interest in Polymeric Delivery Systems is their programmability. The use of these systems provides the potential to control drug delivery both temporally and spatially. A very simple example is sustained drug release from polymeric matrices that generates a continuous plasmatic concentration for a prolonged period within their therapeutic window, similar to non-polymeric drug delivery systems. Polymeric systems for drug delivery can be used for several purposes to improve biopharmaceutical and pharmacokinetic properties of drugs. One of these applications is in the dynamic release of insulin from a polymeric matrix that occurs only in response to increased glucose concentration among diabetic patients. To extend blood circulation time, drugs have been encapsulated in polymeric nano- or micro- particles. Polymer-drug conjugation can also increase drug circulation time and stability in blood. The products obtained from those systems thus improve drug performance, provide patient convenience, and prolong drug stability. Moreover, development of these products can also be less expensive than searching for new drugs. In addition, re-formulation is an effective means of extending patent protection of an existing drug (Leong, Langer, 1987; Pillai, Panchagnula, 2001; Kim et al., 2009).

Polysaccharides are the most popular of all polymer compounds used for drug release systems, due to a number of characteristics that make these materials ideal for phar- maceutical use. These characteristics include the variety of chemical functional groups that can be attached to their chains for both chemical and biochemical modifications, as well as being highly stable, safe, non-toxic, hydrophilic and able to form gels upon hydration. Furthermore, polysaccharides are biodegradable and thus attractive for use in targeted drug-release systems (Sinha, Kumria, 2001; Liu et al., 2008; Kim et al., 2009). Examples of polysaccharides used for drug release include poly (alginic acid), modified starch, dextran and cellulose derivatives, which have all been widely used because they control the release of the drug, albeit through different mechanisms (Adrianov, Payne, 1998; Lopes et al., 2005). Dextran, a polymer produced by microorganisms, is nontoxic, biodegradable, biocompatible and highly hydrophilic. It can be produced in a wide range of molecular weights, giving rise to variable physical and chemical properties, such as different solubilities and viscosities. Dextran is degraded by dextranases in various organs of the human body, such as the liver, spleen, kidney and colon (Ferreira et al., 2004; Hiemstra et al., 2006; Barsbay, Güner, 2007). Dextran and its derivatives are used as plasma expanders, bone regeneration promoters and for skin and subcutaneous filling. Thus, dextrans number among the most promising candidates for the design of hydrogels capable of controlling the release of both small molecule and protein drugs (Barsbay, Güner, 2007; Coviello et al., 2007) and have gained much attention due to their utility in a variety of other applications (Van Thienen et al., 2007). Additionally, dextrans have helped achieve optimal release and desirable therapeutic characteristics in a wide range of systems. Hydrogels prepared from naturally occurring polymers can therefore confer highly beneficial properties to a drug (Hamidi et al., 2008). The objective of this study was to develop a modified release system consisting of a dextran hydrogel containing praziquantel.

\section{MATERIAL AND METHODOLOGY}

\section{Material}

Dextran 70000 (TCI ${ }^{\circledR}$ ), absolute ethanol 99.5\% (Synth ${ }^{\circledR}$ ), hydrochloric acid $37 \%$ (Chemis $\left.{ }^{\circledR}\right)$, sodium lauryl sulphate (BDH Chemicals Ltda.) and Praziquantel (Shangai Pharmaceutical ${ }^{\circledR}$ ) were used as received.

\section{Method}

Preparation of hydrogels and physical mixtures

PZQ and DEX-70 were combined at a ratio of 1:0.5

(w/w) PZQ:DEX-70. PZQ was then incorporated into 
hydrogels by the solvent casting process. Briefly, PZQ was dissolved by stirring in a water-ethanol solution. Dextran was then added. Subsequently, this mixture was placed in a rotary evaporator, and held at $55{ }^{\circ} \mathrm{C}$ until all solvent was removed. Separately, physical mixtures were prepared by weighing PZQ and DEX-70 at the same ratio as above, and mixing. After mixing, the samples were sieved and stored.

\section{Solubility assays}

The solubility of the incorporated PZQ in water was determined by dispersing aliquots of hydrogels containing $10 \mathrm{mg}$ of PZQ in $10 \mathrm{~mL}$ of water, according to the approach adapted from work carried out by Nepal et al. (2010) and Vippagunta et al. (2002). These samples were stirred for $24 \mathrm{~h}$, then centrifuged at $3400 \mathrm{rpm}$ for $10 \mathrm{~min}$ and the amount of dissolved PZQ determined by UV spectrophotometry at $263 \mathrm{~nm}$. The experiments were performed in triplicate and results expressed as mean values.

\section{Sample characterisation}

The systems were characterized by infrared absorption spectroscopy (IR), X-Ray diffraction (XRD) and differential scanning calorimetry (DSC).

\section{Infrared Absorption Spectroscopy}

To investigate the existence of physical or chemical interactions between drug and polymer, absorption spectra in the infrared region were obtained using a Fourier transform infrared spectrophotometer (IRPrestige-21, Shimadzu ${ }^{\circledR}$ ). Samples of PZQ, physical mixture and hydrogels mixed with $\mathrm{KBr}$ were analysed. The IR spectra were recorded and peaks compared to published data.

\section{$X$-Ray Diffraction (XRD)}

The identification of the crystalline structure and/ or amorphous forms of PZQ, DEX, PZQ/DEX physical mixture and PZQ /DEX hydrogels was carried out in diffraction patterns obtained from X-ray diffraction on a Siemens ${ }^{\circledR}$ model D5000 goniometer at a speed of $0.05 / \mathrm{min}$ under $\mathrm{Cu}-\mathrm{K} \alpha$ radiation $(\lambda=1.5406 \AA)$ and scanning X-ray wide angle $2 \theta$ of between 4 and 60 .

\section{Differential scanning calorimetry (DSC)}

For thermal analysis of PZQ, DEX, PZQ/DEX physical mixture and PZQ/DEX hydrogels, a DSC-2910 differential scanning calorimeter (TA Instruments ${ }^{\circledR}$ ), capable of operating from room temperature up to $600{ }^{\circ} \mathrm{C}$, was employed. DSC curves were obtained from samples of 1.9 to $2.1 \mathrm{mg}$ in aluminium crucibles heated at $10{ }^{\circ} \mathrm{C} / \mathrm{min}$ under a nitrogen atmosphere flowing at $25 \mathrm{~mL} / \mathrm{min}$.

\section{Swelling ratio}

The swelling ratio of the samples was recorded over $2 \mathrm{~h}$ in an adapted Enslin device (Cury, 2009). For these tests, a $0.05 \mathrm{~g}$ aliquot of each sample was used, and the volume of water absorbed was assessed at time intervals of $1,5,10,15,20,30,40,60,90$ and $120 \mathrm{~min}$. All assays were performed in triplicate and the results expressed as a percentage of absorbed water relative to the initial sample mass.

\section{In vitro dissolution assays}

The rate of dissolution of PZQ was evaluated for those hydrogels that showed improvement in the water solubility of PZQ. The percentage drug dissolved was estimated by the method described in USP 31 for PZQ tablets, which was adapted to the conditions required to analyse the hydrogel parameters. Samples of free PZQ, hydrogels or physical mixture $(10 \mathrm{mg})$ were incubated in $150 \mathrm{~mL}$ of a dissolution medium composed of $2 \mathrm{mg} / \mathrm{mL}$ sodium lauryl sulphate in $0.1 \mathrm{~N} \mathrm{HCl}$. Aliquots of this medium were withdrawn at 5, 10, 15, 20, 30, 45 and 60 min, filtered and analysed by HPLC. On withdrawal, each aliquot was replaced with fresh medium.

For the HPLC analysis, a Varian - ProStar system for High Performance Liquid Chromatography was used, equipped with two solvent injection pumps (Prostar ${ }^{\circledR} /$ Dynamax $\left.{ }^{\circledR} 210 / 215\right)$, a photodiode assay spectrophotometric detector (Prostar ${ }^{\circledR} 330$ UV-VIS PDA), Star system data integration, an injection system (Rheodyne ${ }^{\circledR}$ VS 7125) with a $100 \mu \mathrm{L}$ loop and a Varian ${ }^{\circledR}$ HPLC octadecyl silane RP 18 column ( $250 \mathrm{~mm}, 5 \mu \mathrm{m}$ particle size). The mobile phases were water (55\%) and acetonitrile (45\%). Aliquots of $150 \mu \mathrm{L}$ of collected sample were injected, and a flow rate of $1 \mathrm{~mL} / \mathrm{min}$ was used.

\section{RESULTS AND DISCUSSION}

\section{Preparation of hydrogels}

Hydrogels have been widely studied as potential systems for drug delivery and, in particular, as a viable means of improving the dissolution rate of poorly water soluble drugs. The small intestine is highly permeable to PZQ, but due to its poor water solubility it has low drug bioavailability. Dextran was chosen as the polymeric carrier as it is a natural polymer with low toxicity, high biocompatibility and biodegradability, and especially because it is hydrophilic. All of these properties are considered ideal for hydrogels.

The hydrogels were prepared in hydroalcoholic solution by the process of solvent casting. In this process, 
ethanol facilitates drug dissolution and also the physical cross-linking of the polymer through intermolecular interactions, such as hydrogen bonding or weaker interactions.

Water then hydrates the polymer, completing the formation of the hydrogel. It is likely that during this formation process, there is competition between ethanol and the polymer for water molecules, causing the drug to be incorporated into the polymer matrix during this process. In the present study, this method proved to be successful and efficient, as well as being easy to execute and low cost.

\section{Solubility Assays}

Figure 1 shows the results of water solubility of PZQ for the different samples. All tests were performed in triplicate and the results correspond to the mean of the three determinations. The solubility of $0.22 \mathrm{mg} / \mathrm{mL}$ for free PZQ served as a control to assess the influence of the polymer carrier on this drug property. The data in Figure 1 show that the hydrogel altered the drug's solubility in water. The solubility of PZQ in the samples of the 1:0.5 PZQ:DEX hydrogel was slightly lower than that of the free drug. This solubility behaviour reflects the fact that dextran is a hydrophilic polymer and PZQ is very poorly soluble in water. Thus, the dissolution of the drug is hindered by the dextran binding to most of the water.

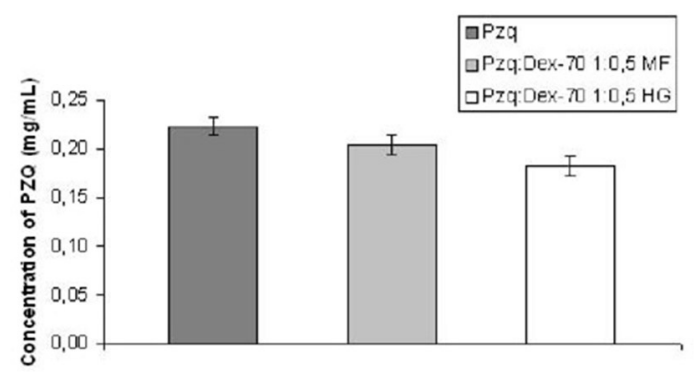

FIGURE 1 - Solubility of PZQ incorporated into hydrogels (Pzq:Dex-70 1:0.5 HG) and physical mixture (Pzq:Dex-70 1:0.5 $\mathrm{MF})$ in water.

\section{Infrared Absorption Spectroscopy}

The PZQ absorption spectrum (Figure 2a) shows an $\mathrm{OH}$ stretching band at $3400 \mathrm{~cm}^{-1}$ which, in this case, is attributed to the presence of water molecules. The bands at $2929.87 \mathrm{~cm}^{-1}$ and $2852.72 \mathrm{~cm}^{-1}$ are $\mathrm{CH}$ vibrations of the symmetric and asymmetric $\mathrm{CH}_{3}$ and $\mathrm{CH}_{2}$ axial deformations, which have previously been observed in PZQ-loaded nanoparticles by Mainardes et al. (2006). According to these authors, a band at $1630 \mathrm{~cm}^{-1}$ stems from carbonyl stretching, and is observed at $1649.14 \mathrm{~cm}^{-1}$ (Figure 2a) in this case. Furthermore, several overlapping bands are seen between 1350 and $1000 \mathrm{~cm}^{-1}$, indicating $\mathrm{CN}$ axial deformation (Mainardes et al., 2006). As noted by Stenekes et al. (2001) and Pitarresi et al. (2007), in the absorption spectrum of dextran (Figure 2b) there is a broad band at $3448 \mathrm{~cm}^{-1}$, resulting from $\mathrm{OH}$ stretching in the polymer chain. Stenekes et al. (2001) also reported the presence of a band at $2900 \mathrm{~cm}^{-1}$ related to $\mathrm{CH} / \mathrm{CH}_{2}$ vibrations, which can be observed at $2922 \mathrm{~cm}^{-1}$ and $2924 \mathrm{~cm}^{-1}$ in this experiment (Figure 2b). Comparing the IR absorption spectra of the physical mixture and the hydrogel (Figure 3), it can be observed that the characteristic functional groups of drug and polymer are maintained, confirming the integrity of the components in each case.
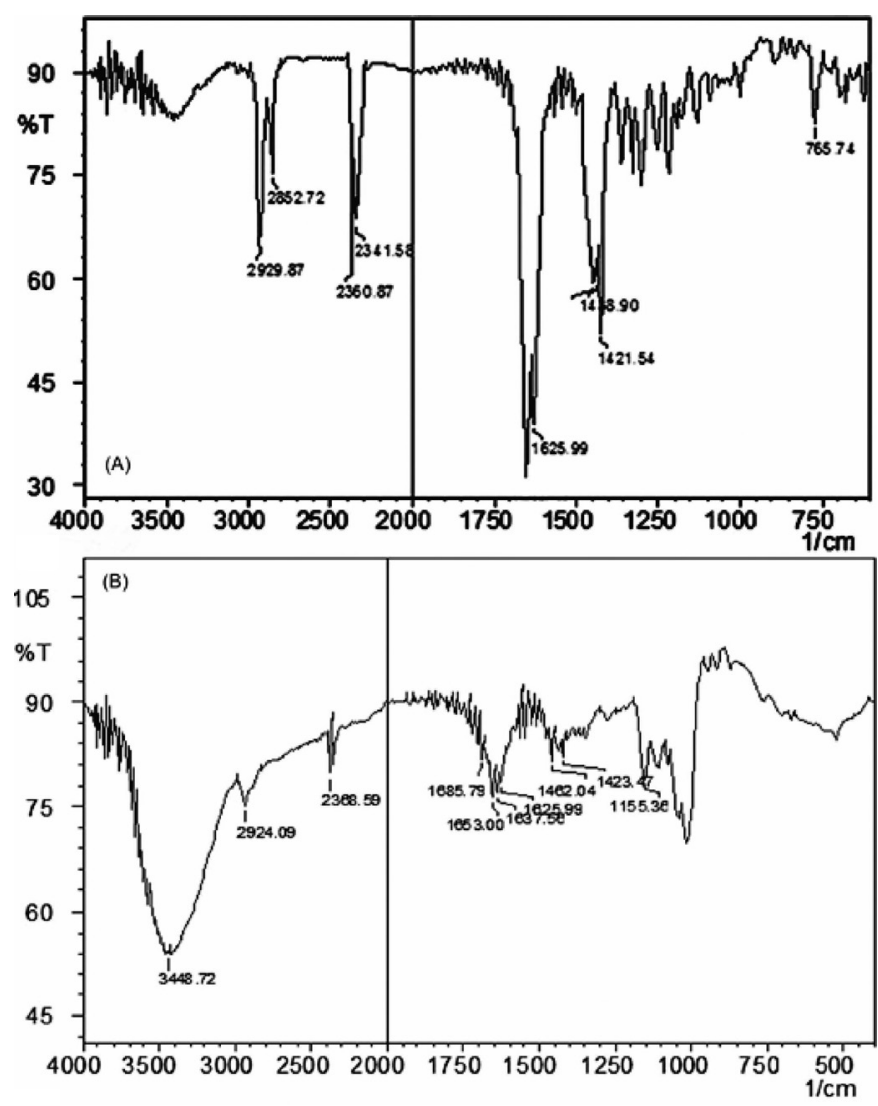

FIGURE 2 - Infrared Spectrum of praziquantel (A) and dextran $70 \mathrm{kDa}(\mathrm{B})$.

\section{X-Ray Diffraction}

Figure 4 show X-Ray patterns of PZQ, DEX, physical mixtures and hydrogel. The X-Ray pattern of free PZQ shows crystalline structure of drug, as demonstrated by sharp and intense diffraction peaks close to $6^{\circ}, 7.5^{\circ}$ and a range of peaks between $10^{\circ}$ and $30^{\circ}$, similar to those observed by Passerini et al. (2006) and Cheng et al. (2010). 

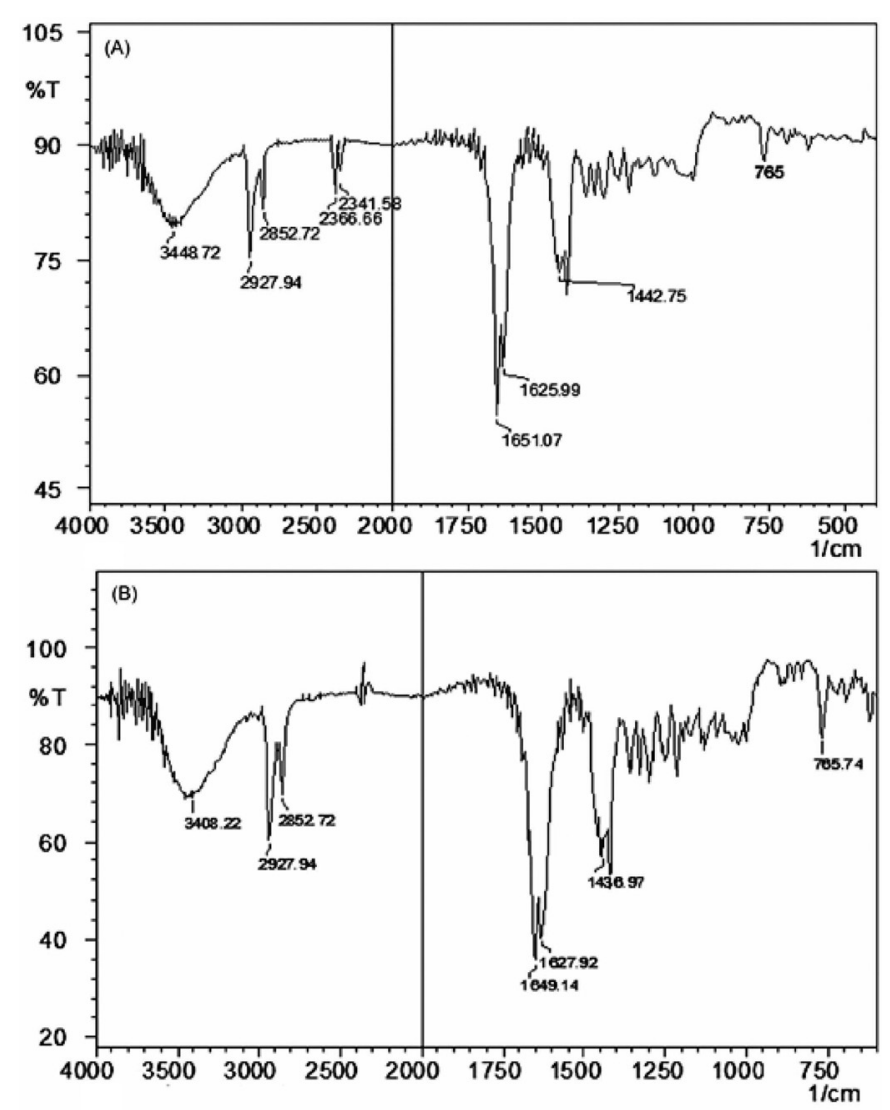

FIGURE 3 - Infrared Spectrum of Physical Mixture PZQ:DEX-70 (A) and Hydrogel PZQ:DEX-70 (B).

Dextran presents a broad peak centered at $2 \theta$ of $18^{\circ}$, suggesting some level of crystallinity, as noted also by Yuan et al. (2009). It is also evident in the physical mixture that PZQ maintained peaks close to $6^{\circ}$ and $7.5^{\circ}$, although the intensity was reduced slightly, whereas the series of peaks between $10^{\circ}$ and $30^{\circ}$ were unchanged. In hydrogel, the x-ray pattern showed some changes, such as the peak around $6^{\circ}$ which did not appear in the pattern and the peak at $7.5^{\circ}$ that was significantly reduced in intensity. Both XRay patterns failed to show evidence of an X-Ray pattern of DEX, probably owing to the concentration of polymer in the formulation. In addition, these results showed that DEX and PZQ did not interfere with each other in the formulation.

\section{Differential Scanning Calorimetry (DSC)}

Figure 5 show DSC curves of PZQ, DEX, physical mixture and hydrogel. In Figure 5a, the DSC curve for praziquantel has a sharp endothermic peak at $137.7^{\circ} \mathrm{C}$. This peak corresponds to the melting point of the drug and indicates that it is crystalline in nature (Hussein, Abdullah, 1998; Mainardes, Gremião, Evangelista,

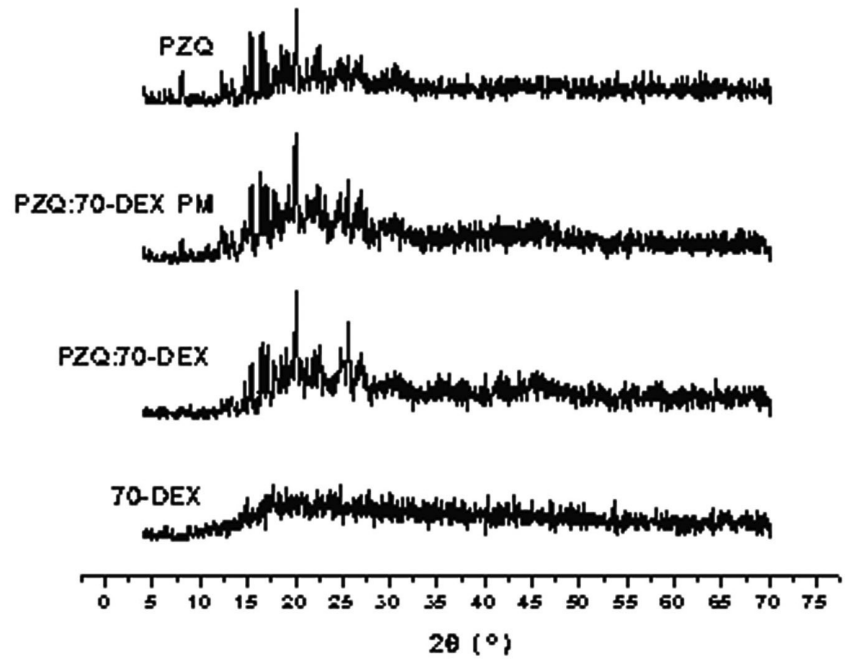

FIGURE 4 - XRD patterns of praziquantel, dextran $70 \mathrm{kDa}$, physical mixture and hydrogel.

2006). As observed by Zhang and Chu (2002), the glass transition of dextran can be seen near $220^{\circ} \mathrm{C}$. This glass transition temperature indicates that there is no crystalline dextran and thus confirms the amorphous structure of the polymer. A possible cause of such a high glass transition temperature could be the existence of strong hydrogen bonds between the macromolecules of dextran (Zhang, Chu, 2002). The PZQ:DEX physical mixture shows an endothermic peak at $139.4{ }^{\circ} \mathrm{C}$ (Figure 5c), indicating that the drug-polymer mixture does not generate changes in the thermal behaviour of PZQ. However, the PZQ-DEX hydrogel exhibited an endothermic peak at $138.7^{\circ} \mathrm{C}$, showing a higher energy input than that observed for the equivalent physical mixture. Furthermore, both of these energy inputs are lower than that required by PZQ (Table I). The amount of energy needed to melt the free PZQ is higher in its pure crystals because the intermolecular interactions are much stronger in $\mathrm{PZQ}$ than those between PZQ molecules incorporated into the hydrogel or those in the physical mixture. It should also be noted that there are interactions between the molecules of PZQ and dextran, but these are extremely weak. The same interactions occur in the hydrogels, but because the drug molecules are further apart within the polymer network formed by dextran macromolecules these occur in a milder form and consequently the amount of energy needed to generate the fusion of PZQ is further reduced.

A summary of data obtained by DSC can be seen in Table I. Based on this data, it can be concluded that there is a weak solid-solid interaction between the polymer and drug, although this did not interfere with the physicochemical properties of the drug, polymer or delivery system to a significant extent. 

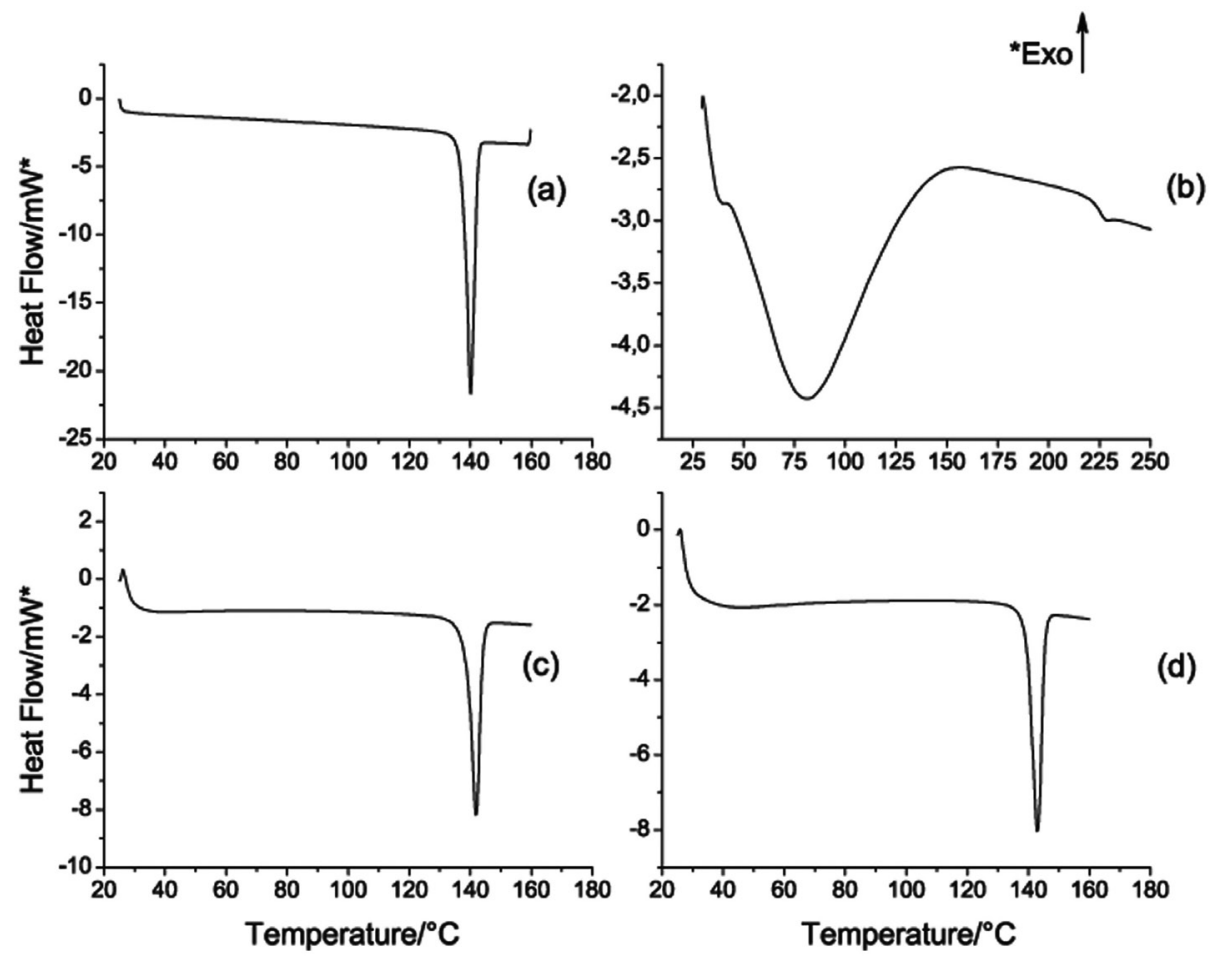

FIGURE 5 - DSC curves of praziquantel (a), dextran $70 \mathrm{kDa}(\mathrm{b})$, the physical mixture PZQ:DEX-70 (c) and the hydrogel PZQ:DEX-70 (d).

TABLE I - DSC data

\begin{tabular}{lccc}
\hline Sample $(\mathrm{mg})$ & $\mathrm{T}_{\text {onset }}\left({ }^{\circ} \mathrm{C}\right)$ & $\mathrm{T}_{\text {peak }}\left({ }^{\circ} \mathrm{C}\right)$ & $\Delta \mathrm{H}(\mathrm{J} / \mathrm{g})$ \\
\hline PZQ & 137.7 & 141.2 & 89.87 \\
DEX70 & - & - & - \\
PZQ:DEX70(1:0.5) & 138.7 & 142.3 & 74.86 \\
MF-PZQ:DEX70(1:0.5) & 139.4 & 143.2 & 64.63 \\
\hline
\end{tabular}

\section{Swelling ratio}

Figure 6 shows the swelling profile of the samples over time. The swelling ratio of samples containing the drug was higher than that of the polymer alone. Initially, the dextran did not show any swelling, but after 40 minutes of contact with the moistened surface of the sintered plate, the polymers began to swell until finally, after 120 minutes, a swelling ratio of $384 \%$ was observed. However, the hydrogels showed a quite different swelling behaviour from that of the free polymer. The dextran hydrogel had a swelling ratio of $58 \%$ at $10 \mathrm{~min}$, gradually rising to $358 \%$ in relation to its original weight at $40 \mathrm{~min}$. It then remained constant until $90 \mathrm{~min}$, after which time it began to increase, continuing to do so until $120 \mathrm{~min}$, at which time it had increased by $536 \%$.

An explanation for this swelling pattern is that dex-

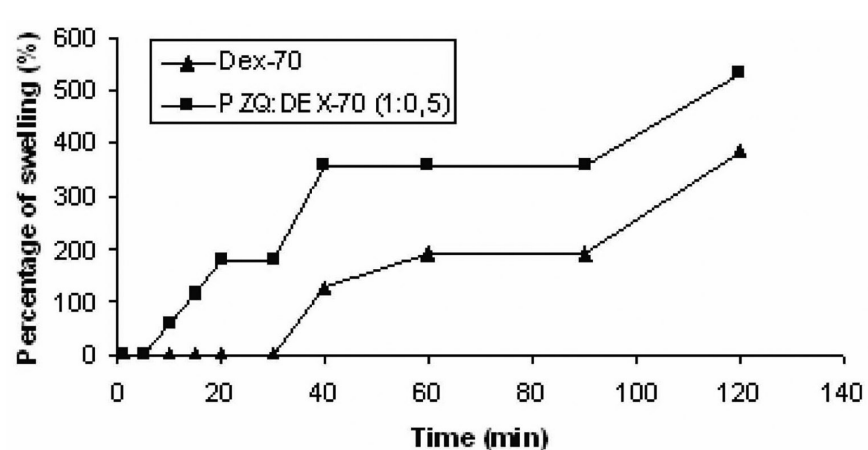

FIGURE 6 - Swelling profile of dextrans 70kDa (Dex-70), and hydrogel containing praziquantel (PZQ:DEX-70 (1:0.5)).

tran is a linear polymer, by more than $50 \%$ of consecutive $\alpha-(1 \rightarrow 6)$ linkage in its main chains, and having side chains starting from branched linkages of $\alpha-(1 \rightarrow 2), \alpha-(1$ $\rightarrow 3)$ and $\alpha-(1 \rightarrow 4)$ (Coviello, 2007). These side chains are more than likely responsible for the physical interaction between the polymer chains and, consequently the formation of the hydrogel networks. The polymer also has a large number of hydroxyl groups, responsible for the polymer's hydrophilicity and probably also for the formation of hydrogen bonds between polymer chains.

Thus, it is plausible that the chains of dextran are bound close together by hydrogen bonds, causing the distance between the hydroxyl groups in the chain to be 
much smaller than the distance between many of the other hydroxyl groups in the same molecule. This tight binding would hinder the entry of water into the polymer network. The presence of the drug may cause a rearrangement of the $\mathrm{OH}$ groups, increasing the distance between various chains of dextran and reducing the amount of free hydroxyl groups able to form hydrogen bonds. This rearrangement, in turn, would make these groups more available for contact with water and thus accelerate hydrogel formation.

\section{In vitro dissolution assays}

Figure 7 shows the results of PZQ release. According to the analysis, the 1:0.5 PZQ:DEX hydrogel sample reached the maximal amount of drug released in $60 \mathrm{~min}$. The maximal amount of drug released was $10.2 \%$, a value much smaller than the $27.6 \%$ from the free drug and the $29.7 \%$ from the physical mixture.

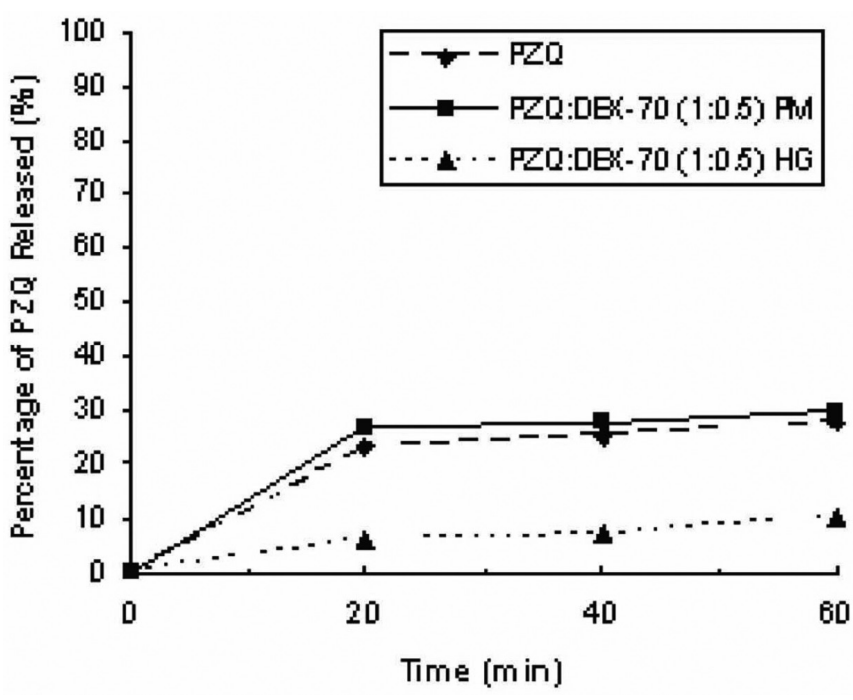

FIGURE 7 - Release Profile of hydrogel PZQ: DEX-70 (1:0.5), their physical mixture and free drug.

From the profile for the 1:0.5 PZQ:DEX hydrogel, a continuous release of the drug was observed, proving that this dextran hydrogel acted as a controlled drug release system. The swelling ratio of hydrogels determines the drug release profile. Therefore, it is possible to show a relationship between the swelling profiles of the dextran hydrogels, noted earlier, and their drug release profiles.

A likely explanation for the observed release profile would be that the hydrogel swelling capacity was affected by a very strong molecular interaction between the polymer chains, despite the likely rearrangement of the $\mathrm{OH}$ groups. These types of interactions have also been reported in DSC analyses. The existing hydrogen bonds likely par- tially hinder the separation of polymer chains, allowing for the entry of water, as seen in the swelling tests, but also obstruct the outflow of the drug, leading to prolonged drug release. This mechanism may afford an improvement in various properties of the drug, such as its bioavailability and half-life, while also reducing its adverse effects.

\section{CONCLUSIONS}

The use of hydrogels as delivery systems for drugs has shown interesting results. In the in vitro release assays, the profile of $\mathrm{PZQ}$ release was prolonged by incorporation into dextran molecules, effectively trapping PZQ in the matrix and releasing it gradually.

Swelling analysis proved to be crucial in the characterisation of the hydrogels. While the physical characteristics of a polymer result from its structural properties, alterations in swelling rate can change the release profile. DSC analysis and IR absorption spectroscopy verified the absence of any strong interaction between drug and polymer.

Finally, in addition to the continuous release of PZQ, the incorporation of the drug into the polymer matrix could give rise to significant changes in several pharmaceutical properties of praziquantel, such as its solubility and dissolution rate.

\section{ACKNOWLEDGEMENTS}

We greatly appreciate and thank Tim Robert for his help in the careful review of this manuscript.

\section{REFERENCES}

ADRIANOV, A.K.; PAYNE, L.G. Polymeric carriers for oral uptake of microparticles. Adv. Drug Del. Rev., v.34, p.155177, 1998.

BARSBAY, M.; GÜNER, A. Miscibility of dextran and poly (ethylene glycol) in solid state: effect of the solvent choice. Carbohydr. Polym, v.69, p.214-223, 2007.

BREDA, S.A.; JIMENEZ-KAIRUZ, A.F.; MANZO, R.H.; OLIVERA, M.E. Solubility behaviour and biopharmaceutical classification of novel high-solubility ciprofloxacin and norfloxacin pharmaceutical derivates. Int. J. Pharm., v.371, p.106-113, 2009.

CHENG, L.; LEI, L.; GUO, S. In vitro and in vivo evaluation of praziquantel loaded implants based on PEG/PCL blends. Int. J. Pharm., v.387, p.129-138, 2010. 
COVIELLO, T.; MATRICARDI, P.; MARIANECCI, C.; ALHAIQUE, F. Polysaccharide hydrogels for modified release formulations. J. Control Release, v.119, p.5-24, 2007.

CURY, B.S.F.; CASTRO, A.D., KLEIN,S.I., EVANGELISTA, R.C. Modeling a system of phosphatated-cross-linked high amylase for controlled drug release Part 2: Physical parameters, cross-linking degrees and drug delivery relationship. Int. J. Pharm., v.371, p.8-15, 2009.

DUNCAN, R. The dawning era of polymer therapeutics. Nat. Rev. Drug Discov., v.2, p.347-360, 2003.

ENK, M.J.; LIMA, A.C.L.; DRUMMOND, S.C.; SCHALL, V.T.; COELHO, P.M.Z. The effect of the number of stool samples on the observed prevalence and infection intensity with Schistosoma mansoni among a population in an area of low transmission. Acta Trop., v.108, p.222-228, 2008.

ETTMAYER, P.; AMIDON, G.L.; CLEMENT, B.; TESTA, B. Lessons learned from marketed and investigational prodrugs. J. Med. Chem., v.47, p.2393-2404, 2004.

FERREIRA, L.; GIL, M.H.; CABRITA, A.M.S.; DORDICK, J.S. Biocatalytic sythesis of highly ordered degradable dextran-based hydrogels. Biomaterials, v.26, p.4707-4716, 2005 .

GIORDANO, F.; BETTINETTI, G.P.; LA MANNA, A.; MARINI, A.; BERBENNI, V. Thermal analysis of a drugpolymeric excipient solid system. J. Therm. Anal. Calorim, v.34, p.531-536, 1988.

GONZÁLEZ-ESQUIVEL, D.; RIVERA, J.; CASTRO, N.; YEPEZ-MULIA, L.; HELGI, J.C. In vitro characterization of some biopharmaceutical properties of praziquantel. Int. J. Pharm., v.295, p.93-99, 2005.

HAMIDI, M.; AZADI, A.; RAFIEI, P. Hydrogel nanoparticles in drug delivery. Adv. Drug Deliv. Rev., v.60, p.1638-1649, 2008.

HIEMSTRA, C.; AA, L.J.V.D.; ZHONG, Z.; DIJKSTRA, P.J.; FEIJEN, J. Novel in situ forming, degradable dextran hydrogels by Michael addition chemistry: synthesis, rheology, and degradation. Macromolecules, v.40, p.11651173, 2007

HUSSEIN, I. EL-SUBBAGH; ABDULLAH, A. AL-BADR. Praziquantel. Anal. Prof. Drug Subs. and Exc., v.25, p.464$500,1998$.
KIM, S.; KIM, J.; JEON, O.; KWON, I.C.; PARK, K. Engineered polymers for advanced drug delivery. Eur. J. Pharm. Biopharm, v.71, p.420-430, 2009.

LEONG, K.W.; LANGER, R. Polymeric controlled drug delivery. Adv. Drug Del. Rev., v.1, p.199-233, 1987.

LIU, Z.; JIAO, Y.; WANG, Y.; ZHOU, C.; ZHANG, Z . Polysaccharides-based nanoparticles as drug delivery systems. Adv. Drug Deliv. Rev., v.60, p.1650-1662, 2008.

LOPES, C.M.; LOBO, J.M.S.; COSTA, P. Formas farmacêuticas de liberação modificada: polímeros hidrifílicos. Rev. Bras. Ciênc. Farm., v.41, p.143-154, 2005.

MAINARDES, R.M.; GREMIÃO, M.P.D.; EVANGELISTA, R.C. Thermoanalytical study of praziquantel loaded-PLGA nanoparticles. Rev. Bras. Ciênc. Farm., v.42, p.523-530, 2006.

MOURÃO, S.M; COSTA, P.I.; MARORA, H.R.; GREMIÃO, M.P.D. Improvement of antischistosomal activity of praziquantel by incorporation into phosphatidylcholinecontaining liposomes. Int. J. Pharm., v.295, p.157-162, 2005 .

NEPAL, P.R.; HAN, H.; CHOI, H. Enhancement of solubility and dissolution of Coenzyme $\mathrm{Q}_{10}$ using solid dispersion formulation. Int. J. Pharm., v.383, p.147-153, 2010.

PASSERINI, N.; ALBERTICI, B.; PERISSUTI, B.; RODRIGUEZ, L. Evaluation of melt granulation and ultrasonic spray congealing as techiniques to enhance the dissolution of praziquantel. Int. J. Pharm., v.318, p.92-102, 2006.

PILLAI, O.; PANCHAGNULA, R. Polymers in drug delivery. Curr. Opin. Chem. Biol., v.5, p.447-451, 2001.

PITARRESI, G.; CASADEI, M.A.; MANDRACCHIA, D.; PAOLLICELLI, P.; PALUMBO, F.S.; GIAMMONA, G. Photocrosslinking of dextran and polyaspartamide derivatives: A combination suitable for colon-specific drug delivery. J. Cont. Rel., v.119, p.328-338, 2007.

SINHA, V.R.; KUMRIA, R. Polysaccharides in colon-specific drug delivery. Int. J. Pharm, v.224, p.19-38, 2001. 
SOOD, A.; PANCHAGNULA, R. Design of controlled release delivery systems using a modified pharmacokinetic approach: a case study for drugs having a short elimination half-life and a narrow therapeutic index. Int. J. Pharm., v.261, p.27-41, 2003.

STENEKES, R.J.H.; TALSMA, H.; HENNINK, W.E. Formulation of dextran hydrogel by cristalization. Biomaterials, v.22, p.1891-1898, 2001.

SUN, Y.; PENG, Y.; CHEN, Y., SHUKLA, A.J. Application of artificial neural network in design of controlled release drug delivery systems. Adv. Drug Del. Rev., v.55, p.1201$1215,2003$.

TAKAKURA, Y.; HASHIDA, M. Macromolecular drug carrier systems in cancer chemotherapy: macromolecular prodrugs. Crit. Rev. Oncol. Hematol., v.18, p.207-231, 1995.

THE UNITED SATAES PHARMACOPEIA (USP 31). The National Formulary (NF 23). By authority of the United States Pharmacopeial Convention. Rockville: United States Pharmacopeial Convention, 2008. p.3056-3057.
VAN THIENEN, T.G.; HORKAY, F.; BRAECKMANS, K.; STUBBE, B.G.; DEMEESTER, J.; DE SMEDT, S.C. Influence of free chains on the swelling pressure of PEGHEMA and dex-HEMA hydrogels. Int. J. Pharm., v.337, p.174-185, 2008.

VIPPAGUNTA, S.R.; MAUL, K.A.; TALLAVAJHALA, S.; GRANT, D.J.W. Solid-state characterization of nifedipine solid dispersions. Int. J. Pharm., v.236, p.111-123, 2002.

YUAN, W.; GENG, Y.; WU, F.; LIU, Y.; GUO, M.; ZHAO, H.; JIN, T. Preparation of polysaccharides glassy microparticles with stabilization of proteins. Int. J. Pharm., v.366, p.154$159,2009$.

ZHANG, Y.; CHU, C.C. Thermal and mechanical properties of biodegradable hydrophilic-hydrophobic hydrogels based on dextran and poly(lactic acid). J. Mater. Sci-Mater. M., v.13, p.773-781, 2002.

Received for publication on 22 ${ }^{\text {sd }}$ April 2012 Accepted for publication on $21^{\text {st }}$ November 2012 
